\title{
Antecedents to Leadership: A CB-SEM and PLS-SEM Validation
}

\author{
Hussein-Elhakim Al Issa ${ }^{1 *}$, Mohammed Khalifa Abdelsalam² \\ ${ }^{1}$ Queen Margaret Business School, Queen Margaret University, EH21 6UU Edinburgh, UK \\ ${ }^{2}$ School of Economics, Finance and Banking, University Utara Malaysia, Sintok 06010, Malaysia
}

Corresponding Author Email: alissaht@gmail.com

https://doi.org/10.18280/ijsdp.160801

Received: 1 November 2021

Accepted: 6 December 2021

\section{Keywords:}

higher education, structural equation modeling (SEM), covariance-based SEM, partial least squares SEM, leadership

\begin{abstract}
The main issue with this paper is to investigate the link between emotional intelligence and transformational leadership and the role of organizational culture as a moderator on that relationship by using two research methods: The covariance-based structural equation modeling (CB-SEM) and partial least squares (PLS-SEM). The study examined a complex model consisting of 60 indicators including moderator effects which used real data. This will help in understanding the respective differences of the two approaches in a setup comprising model specification and parameter estimation. The dual SEM approach represents an important contribution, permitting validation of the model's robustness, and, thanks to the CB-SEM method, to overcome the limitations of PLS-SEM. The findings show that both methods yield similar results with minor differences that may be attributed to their respective estimation requirements including model fit and complexity issues. After considering these results and findings from studies done in this line, the researcher concludes that future studies need to observe recommendations made to focus on the phenomenon and research design aspects and, not mere modeling. A study limitation is not testing SEM boundaries with non-normal data and small sample size. The study is first to apply SEM approaches to verify results of a complex leadership model that included moderator affects. A key implication is the insight gained about the application of standards and guidelines for clarifying the interpretation of the SEM theories and models for leadership and management research. This implies the equal use of the CB-SEM and PLS-SEM for future studies, without undue bias.
\end{abstract}

\section{INTRODUCTION}

Many management journals are inclined to prefer certain traditional research designs that they regard as more robust [1, 2]. Therefore, several scholars call for methodological innovations to increase questions researchers ask and improve the credibility of their solutions [3, 4]. Suggestions have included improving the quality criteria and using methods that avoid bias in quantitative research. The current study responds by paying special attention to the examination of two popular research methods in quantitative management research: the covariance-based structural equation modeling (CB-SEM) and partial least squares (PLS-SEM).

Structural equation modeling (SEM) explains the structure of the interrelationships expressed in a series of equations [5]. It refers to statistical techniques that examine relationships between independent and dependent variables within a proposed causal structure [6,7], albeit multivariate techniques which help to explain theories with statistical efficiency. However, SEM can only study one relationship at a time. Despite this, SEM can define whole models and represent unobserved concepts. The aim of the present study is to assess the strengths and weaknesses of SEM in the context of leadership development. This is done by validating covariance-based SEM (CB-SEM) with variance-based SEM (PLS-SEM). Both methods analyzed latent constructs' cause and effect relationships, but their results may or may not be the same because of their different assumption and estimation procedures [5]. The CB-SEM and PLS-SEM were utilized to study the data by validating the requirements, specifications, and the results of each method. This study surveys university leaders for their transformational leadership (TL) by also examining the constructs of emotional intelligence (EI), and organizational culture (OC). Past studies found that EI-TL association inconsistent $[8,9]$ and little is known about OC moderation even though it has been found to influence both TL $[10,11]$ and EI [12, 13]. Therefore, the current study investigates EI-TL relationship and the role of $\mathrm{OC}$ as moderator.

The CB-SEM analyzes variables and error terms that are estimated together in one unified model. It can prevent measurement errors, but it would require variables to conform to some proportionality constraints. This then results in unbiased parameter estimates. The PLS-SEM, alternatively, does not allow modeling to have the measurement error and it does not require proportionality constraints. Thus, it produces biased parameter estimates. It weighs composites instead of common factors. Formative measurement generates identification difficulties in the CB-SEM but not in the PLSSEM [14]. Nonetheless, careful consideration of the properties and capabilities of the CB-SEM and the PLS-SEM can be most beneficial after observing the recommendations made by Rigdon et al. [1]. The recommendation includes, first, to focus on the phenomenon and research design aspects and not just 
on mere modeling. Second, assuming that it is known, it is advised to use the CB-SEM if estimating a factor model, but to use the PLS-SEM if estimating a composite-based model. Third, as the research program progresses, it would show indications on which approach produces the best proxies. Lastly, researchers must regularly explore different models that are theoretically acceptable to explain their concepts.

A validation using the two approaches is useful because both methods differ in assumptions, outcomes, and estimation procedures. This allows us to learn how their results may or may not differ in different situations. The "PLS-SEM estimates the parameters so that the explained variance of the endogenous latent variable(s) is maximized" [5] while the CBSEM estimates parameters. This means that differences between the sample covariances and those predicted by the theoretical model are minimized [5]. Validating the SEM approaches can better our understanding and interpretation of SEM models. Further, "such assessments would help disclose the different methods' efficacy for different situations that researchers encounter in their studies" [15]. Put differently, research can uncover which suboptimal situations would have which feature of each approach falling short, and for what reasons [1].

There is no clear and certain answer as to whether the CBSEM and the PLS must produce identical results if the structure of the two models being assessed is alike [1]. Therefore, this study aims to verify whether both methods would yield the same conclusions by addressing the requirements for optimal performance of each method. The outcome would be able to untangle the differences when these two approaches are used within a complex model that consists of real data, and when their respective setup specifications and parameter estimations are met. This is done by using the consistent PLS method [16, 17] while observing all research integrity recommendations as proposed by Rigdon et al. [1]. In the current study, the PLS method is used to reduce the impact of measurement error, following [18] recommendation who had mentioned that the PLS method uses weighted composites only if indicator reliabilities were mixed, the sample large, and the composites are correlated.

Many articles have been written in this line of research with some notable heated debates Appendix 1, like ref. [19], who assumed that model specification is the only meaningful condition for differentiating the performance of the different approaches. Their study evaluated the relative performance of the CB-SEM and the PLS regarding parameter recovery, under different experimental conditions encompassing sample size, data distribution, and model specification. It was found that covariance structure analysis tended to recover parameters better than the PLS. Willaby et al. [20] introduced the PLSSEM to examine complex models, and comparing it with CBSEM. The study found that the PLS-SEM produced results that were like those of the CB-SEM for a simple mediation model. The PLS can also produce results for a complex model for which the CB-SEM would require a prohibitively large sample. Henseler et al. [21] then summarized the latest developments of the PLS by concluding that there was no clear-cut resolution for this trade-off between efficiency and robustness with respect to model misspecification. Henseler et al. [21] performed a simulation study which had inferred that the PLS was preferable, particularly in the situation when the data were not known to be common factor-based or composite-based. Hair et al. [22] had used the composite model data instead of the common factor model for defining a population. Their results showed that each approach had certain strengths and weaknesses, which made the approach a suitable one when the emphasis is on parameter precision particularly in the measurement model, the structural model, or on statistical power. Hair et al. [5] also offered rules of thumb for selection between the two approaches. Sarstedt et al. [23] noted that the CB-SEM has been marked as "hard modeling" because of its many and restraining assumptions while the PLS-SEM bias involves overestimating the measurement parameters and underestimating the structural ones.

Rönkkö et al. [24] used statistical justifications to cast doubts on the PLS-SEM's effectiveness for building and testing the theory. Likewise, McIntosh et al. [7] explained that the PLSc is no match for SEM's estimation, grounded on the common factor-based modeling. This is because it cannot deal with the universal issue of correlated measurement errors. It was also stressed that the PLS-SEM is an attempt to imitate the common factor-based CB-SEM while the CB-SEM can be reparametrized in diverse fashions to deal with composite variables. Nonetheless, Henseler et al. [18] declared that the supposed deficiencies were not because of the problems with the PLS itself, but rather the techniques used by Rönkkö et al. [24]. Appendix 1 further illustrates.

Despite everything, a more neutral position was taken by $[25,26]$ who concluded that the two approaches would always yield identical results, and that differences lie in the setup of the two methods' specifications and estimations. Marcoulides and Chin [26] also agreed with Treiblmaier et al. [27] who stated that the comparison of approaches must begin by distinguishing the models that have composite variables and latent variables and implementing approximations. Finally, Rigdon et al. [1] suggested five perspectives, hence five recommendations of the approaches instead of comparing CBSEM and PLS-SEM.), namely, concentrate on the phenomenon and not just modeling, remember the importance of design, use CB-SEM to estimate factor models, and PLS for estimating composites, decide on the mode to be estimated, and investigate and justified different models.

\section{LITERATURE REVIEW}

This study was motivated by the persisting issues of leadership in Malaysia's institutions of higher education [28]. The Ministry of Higher Education in Malaysia identified a leadership gap, subsequently prescribing transformational leadership (TL) as the means to overcome these challenges, and to drive performance. It was observed that the available leadership training programs were "content-heavy" and considered as "outdated and redundant" [29]. It is hoped that this study would be able to raise the awareness levels of the people involved besides inspiring subordinates to rise above self-interests [30], thus transforming followers into leaders and leaders into agents of change. Past studies found mixed results on the link between emotional intelligence (EI) and TL, hence the current study includes organizational culture (OC) as a moderator to find an explanation for the relationship [10].

\subsection{Transformational leadership}

Burns [31] was among the first to popularize the TL style when he used the transactional leadership and TL concept to describe the differences between the behaviors of political leaders. The first characteristic of TL is idealized influence, 
where leaders act as strong role models for the followers. The second is inspirational motivation where leaders communicate high expectations to the followers by inspiring them to become committed to a shared vision. The third is intellectual stimulation where leaders stimulate creativity and innovation by challenging the beliefs and values of the followers. The last of these characteristics is individualized consideration where leaders provide a supportive climate by listening to the followers. There is ample evidence highlighting its effectiveness $[32,33]$, very strong intuitive appeal, and widely used approach. While TL has been studied in various organizations including universities, its examination with EI as a predictor, and $\mathrm{OC}$ as a moderator has been noted to make nascent theoretical insights.

\subsection{Emotional intelligence}

Effective leaders depend on their emotional charms to help them convey their communications, and since "you can't divorce emotions from the workplace because you can't divorce emotions from people" [34], it is very natural to include EI in a study on leadership. At the lowest level of EI branches, self-emotion appraisal, is concerned with identifying emotions in ourselves and in others. Other emotional appraisal is the ability to use emotions to facilitate thinking and to describe how emotional events promote intellectual processing. An additional ability noted in the model is the use of emotion, i.e., the ability to comprehend emotions, emotional language, and the hints carried by emotions and connecting these to situations. The last ability is the regulation of emotion which constitutes the ability to manage emotions to reach precise goals.

\subsection{Organizational culture}

The reason most often cited for organizations failing to perform is their disregard for OC, i.e., failing to alter the organization's culture wrecked by previous changes [35]. Schein [36] asserted that we cannot study leadership without culture as they are integral concepts. Cameron and Quinn [37] described organizational culture as " $\mathrm{OC}$ is reflected by what is valued, the dominant leadership styles, the language and symbols, the procedures and routines, and the definitions of success that make an organization unique". Consequently, researchers have suggested using forms of culture as a moderator in the EI-leadership relationship like Hofstede's cultural dimensions [38]. Others suggested using cultural moderators to test the validity of and confirm the comprehensiveness of emotional intelligence by relating it to different cultures $[9,39]$. Based on this, there is an excellent opportunity for the current study to examine organizational culture, both as a moderator and in a different cultural setting, outside of the western setting.

\subsection{Hypotheses development}

Many theories have explained the developmental changes that people undergo over the course of their lives. The framework of the present research was developed based on social cognitive theory (SCT) as developed by Bandura [40]. The social cognitive theory postulates that individuals learn their behavior from work environments through observations, imitations, and modeling. The main concept in the SCT is reciprocal determinism, which proposes that internal mental events like emotional intelligence and transformational leadership abilities and traits, external environmental events like organizational culture, and plain behavior like transformational leadership behavior, can all influence one another.

Past research had investigated leadership with EI, and the findings derived showed inconsistent associations [41, 42]. Therefore, one of the main objectives of the current study is to evaluate the relationship between EI dimensions and TL in the context of the Malaysian institutions of higher education while validating the examination of the two SEM approaches. To demonstrate the relevance of validating the CB-SEM and the PLS-SEM, the study's model was thus examined through both methods. Likewise, the potential moderating effects of OC on the relation between the dimensions of EI and TL were also examined. Therefore, this study aspired to achieve the following three objectives:

1. To evaluate the relationship between EI dimensions and TL.

2. To determine the role of $\mathrm{OC}$ as a moderator in the relationship between EI dimensions and leadership.

3. To reveal the advantages and disadvantages of using the CB-SEM and the PLS-SEM approaches in a complex model involving a larger sample which includes 60 items and a moderating variable.

Transformational leaders communicate and encourage to commit followers to a shared vision. In this regard, they need symbols and emotional appeals in the form of pep talks, sometimes to focus their efforts on a given direction. In TL, the leaders' ability to stay positive is his/her biggest asset in motivating. This is accomplished by expressing an inspirational vision that lifts when followers are demoralized. All these abilities are part and parcel of the EI domain [43]. Thus, the ability to perceive emotions accurately sets the groundwork for one to become a role model and to be confident enough to connect with followers. Being able to perceive other people's emotions and use one's emotions to facilitate thought processes can boost one's creativity in problem-solving. By the same token, understanding emotions may also enable one to act as a strong role model who can be trusted to do the right thing because of the great trust placed in the leader. Finally, the regulation of emotions involves controlling one's temper and emotional expression. The leader's ability to manage his/her emotions can aid in the attainment of specific goals which are strong and complex to manage.

OC is proposed as a situational determinant that impacts the way EI affects the leadership process. Undoubtedly, a strong culture has standards that are clear for measuring appropriate behaviors. As such, the ability to control and elicit anger, for instance, in situations of injustice, is an example of separation of emotion from behavior. This means that, in some instances, EI (particularly, managing emotions) will be moderated by culture to influence leadership. Goleman et al. [44] recommended using a viable moderator as a possible solution to resolve the inconsistent results. Hence this study examines OC as a primary and reasonable choice [44]. Many studies [11, $12,14]$ have found that OC influenced both TL and EI. In the present study, it was expected that EI abilities would relate with TL in the presence of $\mathrm{OC}$ to facilitate the interaction.

Culture provides guidance for understanding and deriving meanings. Since OC impacts how people understand and react to affective events, it is an important factor for moderating the connection between the utilizing emotions to assist the thought 
process for intellectual stimulations. For example, the leader's emotional facilitation of thought is valuable to a leader who is interested in motivating the followers to a higher level of creative problem-solving. The more the cultural norms are in line with the leaders' emotional signals in building a role model and vision for the followers, the more impact the culture will have on the relationship. This means that the ability to understand emotions, emotional language, and emotional signals are valuable to a leader who acts as the role model, and who sets the vison for his/her followers. Finally, the regulation of emotions may have important consequences in tough situations than in easy ones because of the nature of behaviors expected in difficult situations. Thus, the OC is expected to facilitate the interaction between EI and TL. This is because some organizational cultures have clear standards/measures for measuring appropriate behavior. Based on the logic mentioned above, the following hypotheses were put forth:

H1: Self-emotional appraisal (SEA) is positively and significantly related to TL.

H2: Others' emotional appraisal (OEA) is positively and significantly related to TL.

H3: The Use of Emotion (UOE) is positively and significantly related to TL.

H4: The Regulation of Emotion (ROE) is positively and significantly related to TL.

H5: OC positively moderates the relation between SEA and TL. TL.

H6: OC positively moderates the relation between OEA and TL.

H7: OC positively moderates the relation between UOE and

H8: OC positively moderates the relation between ROE and TL.

\section{METHODOLOGY}

\subsection{Measures}

A questionnaire based on three well-known scales was put together. To measure TL, 20 items were adopted from the MLQ5x [45]. Scores were based on the 5-point Likert- scale, ranging from 1 (not at all) to 5 (Frequently, if not always). The TL measures five dimensions: i) idealized influence (behavioral), ii) idealized influence (attributed), iii) inspirational motivation, iv) intellectual stimulation, and v) individualized consideration.

Emotional intelligence (EI) was measured using Wong and Law's Emotional Intelligence Scale (WLEIS) [46] with scores based on the 5-point Likert scale ranging from 1 (strongly disagree) to 5 (strongly agree). This was based on four dimensions: i) self-emotional appraisal, ii) other's emotional appraisal, iii) use of emotion, and iv) regulation of emotion.

OC was measured using the Organizational Culture Assessment Instrument (OCAI) instrument adopted from [37]. The measure contains four dimensions that contain six items each, thereby resulting in 24 items, namely, i) clan, ii) adhocracy, ii) market, or iv) hierarchy. The instrument utilizes a 5-point Likert-scale ranging from 1 (strongly disagree) to 5 (strongly agree).

\subsection{Sampling}

The Sampling frame is a listing of all the eligible sampling units or elements in the population from which the potential sample was drawn [47]. Public institutions of higher education listed in the Malaysian Ministry of Higher Education directory (Individual public universities and Malim Sarjana websites, retrieved as of August 2012) were used to generate the sampling list for this study. The choice was based on two reasons. Firstly, the directory is accessible to the public, and it contained a published official directory with the necessary information on the public universities. This directory has also been used as a data source in previous leadership studies in Malaysia [48]. A debatable point was whether the listing had been updated regularly. Nonetheless, this study believes that the data availability concern merited greater priority as compared to this limitation [47]. Further, the directory provided all the important information needed by this study to draw the intended respondents.

Sampling for the current study was done through stratified random sampling as recommended by Sekaran and Bougie [47]. This helped to achieve its representativeness, efficiency in situations when differentiated information about various strata within the population is desired. The questionnaire was administered in person over a four-month period. A total of 18 public universities in peninsular Malaysia, with an estimated total of 2076 academic leaders, were approached. Academic leaders constituted the Deans, Deputy Deans, Department heads, Managers, and Directors. During the data collection phase, it was necessary to make follow-up phone calls and visits in-person to the particularly busy academic leaders. Research assistants were recruited to assist with the retrieval of questionnaires distributed to part of the samples and to do the follow-up task by phone and in-person. The minimum sample size was determined to be 325 , which was calculated using [49] sampling formula. Nonetheless, this figure was doubled to minimize the sampling error, and to address the possibility of low response rate. The minimum sample size was further confirmed with a priori $\mathrm{G}^{*}$ Power analysis (versus posteriori) at 92 to detect an effect size of .15 with .8 power at the alpha level of .05 [50]. Of the 650 questionnaires distributed, 347 sets of questionnaires were returned (total usable 333 ), gaining a response rate of $54.4 \%$. The normal response rate noted in Malaysia was between 15 to 25 percent, depending on the method used.

\section{DATA ANALYSIS}

\subsection{Data preparation and analysis of survey response}

SPSS v20 was used to deal with the missing data, outliers (Mahalanobis distance), normality, linearity, multicollinearity, and homoscedasticity. All assumptions and measurement model evaluations when using the CB-SEM, were observed. This encompasses confirmatory factor analysis, common method variance (CMV) as well as normality. These were employed to examine the research framework and hypotheses.

For this study, questionnaires with missing data exceeding four items were removed, and the occasion that occurred should be no more than 12 occasions. Fidell [46] had suggested that mean substitution would be the easiest way to replace the missing values, on the condition that the total percentage of the missing data was $5 \%$ or less. Therefore, out of every collected questionnaire that had four or fewer items missing ( $5 \%$ of 65 items), the mean substitution was used in place of the missing data by using the designated SPSS 
function. The next step was to ensure that data were "clean" by using frequency descriptive statistics. This confirmed that there was no further missing data.

Measurement error is an important issue in quantitative research; it highlights the difference between the true value of the variable and the value obtained by measurement. There are many sources of measurement error, including poorly worded questions in the questionnaire, misunderstanding of the scaling approach, and incorrect application of the statistical method. In the current study, several steps were taken to minimize the measurement errors. This included a pilot test of the instruments. This was conducted earlier to get feedback on the ease of the measure and testing environment. The next step was to ensure that the researcher was available for explaining the questionnaire items to the respondents. The third step was to double-check the data thoroughly after collection, and during data entry for analysis. Lastly, the SPSS missing data features were used to verify any overlooked data.

To confirm the absence of non-response, bias a sample ttest was carried out. No significant difference between early and late respondents was found; the t-test results contained $p$ values of above .05 [51]. The Mahalanobis output from the SPSS using all the 60 items in the test had produced a range of between 9.33 and 161.9, with no cases exceeding the identified critical chi-square value of 418.5 . Since all the values were below the cut-off point per [50] recommendation, this confirmed the non-existence of the outliers' observations. Tests for normality of all variables were done using the Q-Q plot, which was very close to a straight line while the histogram was a bell shape. Data were also found to be multivariate normal as shown by Mardia's coefficient test. It demonstrated the $\mathrm{p}$ values to be above .05 and a reading of .13 and .27 for skewness and kurtosis, respectively. Multicollinearity was checked through Pearson's correlation, which showed that the highest correlation of . 60 was between SEA and ROE, less than the .70 cut-off point. Therefore, all variables were retained. Additionally, VIF (variance-inflated factor) output obtained from SPSS was below 5, with tolerance values of above .20. This confirmed that there were no multicollinearity issues. The assumption of homoscedasticity was also assessed using regression in the SPSS, and it showed that all the independent variables did not violate the assumption of homoscedasticity in the scatter plots, as per [5].

The effect of CMV was remedied by protecting anonymity, by decreasing the evaluation uneasiness, and by improving the understanding of items which were explained one by one to respondents before they filled the questionnaire. Finally, Harman's single factor test was used. The analysis produced thirteen factors which explained a $64.9 \%$ of the variance; with the largest explaining $23.2 \%$ of the total variance and that was below $50 \%$.

\subsection{CB-SEM}

SEM is a term that includes many statistical models. However, covariance-based SEM (CB-SEM) is the commonly used approach in SEM, but PLS-SEM seems to be gaining popularity among researchers. They are considered second generation statistical approaches, distinguished from first generation methods, in that they enable researchers to be more flexible in developing complex and realistic structural and measurement models. SEM enables researchers to evaluate measurement models and structural paths with multiple dependable variables and latent constructs with many items. In social sciences research, SEM is used because of its ease of access but a deep understanding is important to know when to use SEM, its requirements and interpretation when compared to other approaches.

CB-SEM fit is based on estimating the observed covariance matrix which requires the specification of the full theoretical model before data analysis. We start with the confirmatory factor analysis (CFA) performed to examine the factor structure, and to also validate the measurement scales. This was achieved through AMOS v23 [52]. A point of consideration here is that splitting data for exploratory factor analysis (EFA) and CFA seems to depend on schools of thought on the matter and it depends on the purpose of the factor analysis and the situation and not a clear-cut question as elaborated in meta-analysis work by Izquierdo et al. [53]. When the CFA did not attain satisfactory fit while minding the dimensions theorized by [45], an EFA was performed. After a few repetitions, and after the weaker indicators were removed, a unidimensional construct surfaced (see Table 1). At this point, eight out of the $20 \mathrm{TL}$ indicators were eliminated. An EFA was completed to determine the underlying structure of the instrument to observe the possible effect that a different research setting could have on the core nature of the construct dimensionality [54]. Researchers also noted whether items elimination in EFA may affect shifts to the meaning of the construct. At its core TL items observed a flexible leadership style that encourages followers, expanding their interests and leading to embracing of the team's objective [30, 55]. Typically, reflective measure items must share the same theme because they correspond a sample of items that are similarly reliable and interchangeable [56].

Table 1. Exploratory factor analysis

\begin{tabular}{|c|c|c|}
\hline Code & $\begin{array}{c}\text { Variables } \\
\end{array}$ & Loadings \\
\hline IIA1 & $\begin{array}{l}\text { I re-examine the critical assumptions to } \\
\text { question whether they are appropriate }\end{array}$ & 0.647 \\
\hline IIA2 & $\begin{array}{l}\text { I talk about my most important values and } \\
\text { beliefs }\end{array}$ & 0.373 \\
\hline IIA3 & $\begin{array}{l}\text { I seek differing perspectives when solving } \\
\text { problems }\end{array}$ & 0.503 \\
\hline IIA4 & I talk optimistically about the future & 0.637 \\
\hline IIB1 & $\begin{array}{l}\text { I instill pride in others for being associated } \\
\text { with me }\end{array}$ & 0.594 \\
\hline IIB2 & $\begin{array}{l}\text { I talk enthusiastically about what needs to } \\
\text { be accomplished }\end{array}$ & 0.534 \\
\hline IM1 & $\begin{array}{l}\text { I go beyond self-interest for the good of the } \\
\text { group }\end{array}$ & 0.631 \\
\hline IM2 & $\begin{array}{l}\text { I treat others as individuals rather than just } \\
\text { as a members of the group }\end{array}$ & 0.571 \\
\hline IM3 & $\begin{array}{l}\text { I act in ways that build others respect for } \\
\text { me }\end{array}$ & 0.614 \\
\hline IM4 & $\begin{array}{l}\text { I consider the moral and ethical } \\
\text { consequences of decisions }\end{array}$ & 0.326 \\
\hline IS1 & I display a sense of power and confidence & 0.400 \\
\hline IC1 & I help others develop their strengths & 0.362 \\
\hline
\end{tabular}

Preceding the PCA, the correlation matrix showed coefficients at .3 and above. The Kaiser-Meyer-Olkin value was .91 and Bartlett's Test of Sphericity was significant [57]. During the EFA, the 20 items of the Transformational Leadership Scale (MLQ5x) were subjected to principal components analysis (PCA), by using SPSS v20. The EFA uncovered two components at $40.1 \%$, but after performing Oblimin's rotation, only one factor had strong loadings and the second one had negative ones. This result was similar to past 
research on the PANAS Scale $(r=-.43)$ [51]; hence the EFA resulted in a unidimensional TL with 12 indicators to be used for further analysis.

Table 2. Reliability and validity - transformational leadership

\begin{tabular}{cccc}
\hline Variables/ Indicators & Loadings & AVE & CR \\
\hline Transformational & & $(0.38)$ & $(0.87)$ \\
Leadership $(T L)$ & & 0.34 & 0.83 \\
IIA2 & $(0.56)$ & & \\
& 0.51 & & \\
IIA3 & $(0.51)$ & & \\
IIA4 & 0.45 & & \\
IIB1 & $(0.61) 0.5$ & & \\
& $(0.52)$ & & \\
IIB2 & 0.47 & & \\
& $(0.72)$ & \\
IM1 & 0.71 & \\
& $(0.58)$ & & \\
IM2 & 0.54 & \\
& $(0.74)$ & \\
IM3 & 0.73 & \\
& $(0.79)$ & \\
IM4 & 0.72 & \\
& $(0.71)$ & \\
IS1 & 0.66 & \\
IC1 & $(0.47)$ & \\
\hline Notes: All the values in parenthesis are for PLS-SEM; others are for CB-SEM
\end{tabular}

Table 3. Reliability and validity - emotional intelligence

\begin{tabular}{|c|c|c|c|}
\hline Variables/Indicators & Loadings & AVE & $\mathbf{C R}$ \\
\hline Self-Emotional & & $(0.88)$ & $(0.65)$ \\
\hline Appraisal (SEA) & & 0.55 & 0.83 \\
\hline SEA1 & (0.76) 0.57 & & \\
\hline SEA2 & $(0.85) 0.8$ & & \\
\hline SEA3 & (0.84) 0.82 & & \\
\hline SEA4 & (0.79) 0.75 & & \\
\hline Others Emotional & & $(0.75)$ & $(0.92)$ \\
\hline Appraisal (OEA) & & 0.66 & 0.88 \\
\hline OEA1 & (0.80) 0.65 & & \\
\hline OEA2 & (0.88) 0.81 & & \\
\hline OEA3 & (0.87) 0.85 & & \\
\hline OEA4 & (0.91) 0.91 & & \\
\hline & & $(0.68)$ & $(0.90)$ \\
\hline Use of Emotion (UOE) & & 0.58 & 0.85 \\
\hline UOE1 & (0.82) 0.74 & & \\
\hline UOE2 & (0.80) 0.72 & & \\
\hline UOE3 & (0.86) 0.81 & & \\
\hline UOE4 & (0.83) 0.76 & & \\
\hline Regulation of Emotion & & $(0.76)$ & $(0.93)$ \\
\hline$(R O E)$ & & 0.67 & 0.89 \\
\hline ROE1 & (0.87) 0.83 & & \\
\hline ROE2 & (0.88) 0.85 & & \\
\hline ROE3 & (0.85) 0.77 & & \\
\hline ROE4 & (0.88) 0.83 & & \\
\hline
\end{tabular}

Notes: All the values in parenthesis are for PLS-SEM; others are for CB-SEM

Another CFA was carried out by using the six constructs and 52 indicators, including $\mathrm{OC}$, as a second-order construct. The CFA results showed a deficiency of fit $\left(\mathrm{X}^{2}=3387.9\right.$; DF $=1695 ; \mathrm{p}=0.000 ; \mathrm{x}^{2} / \mathrm{df}=1.999 ; \mathrm{GFI}=.725 ; \mathrm{CFI}=.827$; RMSEA $=.055$; PGFI $=.671)$. An acceptable model fit was achieved after examining the loadings, and upon eliminating four further indicators, making the remaining indicators for further CB-SEM analysis to be 48 only. The Chi-square for the model fit was now 1750.652 (1055 degrees of freedom), with a $\mathrm{p}=0.000$. The ratio $\mathrm{x}^{2} / \mathrm{df}$ was 1.659 , which met the cut-off point of less than 5. The comparative fit index (CFI) was .916 (cut off rule of thumb is above 0.9), goodness of fit index (GFI) was .823 (which was close to the rule of thumb of being above .9), and the root mean square error of approximation (RMSEA) was .045. The TLI was .91, which was less than the 0.08 , but over the 0.9 cutoff points, respectively (Figure 1 ). As such, the model fit for the measurement model was acceptable since the important indexes from the three categories of model fit, namely absolute fit, incremental fit, and parsimonious fit, achieved acceptable levels [57]. However, the remaining values were most likely inflated by the study's larger sample size (333) and model complexity (48 items with 6 variables). Tables 2, 3, and 4 illustrate the convergent validity and reliability.

Table 4. Reliability and validity - organizational culture

\begin{tabular}{|c|c|c|c|}
\hline $\begin{array}{c}\text { Variables/Indic } \\
\text { ators }\end{array}$ & Loadings & AVE & CR \\
\hline Organizational & & $(0.43)$ & $(0.95)$ \\
\hline Culture (OC) & & 0.83 & 0.95 \\
\hline \multicolumn{4}{|l|}{ Clan } \\
\hline OL1 & (0.82) 0.72 & & \\
\hline ME1 & (0.86) 0.79 & & \\
\hline OG1 & (0.83) 0.8 & & \\
\hline SE1 & (0.86) 0.82 & & \\
\hline SC1 & (0.86) 0.83 & & \\
\hline \multicolumn{4}{|l|}{ Adhocracy } \\
\hline $\mathrm{DC} 2$ & (0.59) 0.49 & & \\
\hline OL2 & 0.71 & & \\
\hline ME2 & (0.69) 0.6 & & \\
\hline OG2 & (0.76) 0.73 & & \\
\hline SE2 & (0.81) 0.79 & & \\
\hline $\mathrm{SC} 2$ & (0.77) 0.71 & & \\
\hline \multicolumn{4}{|l|}{ Market } \\
\hline DC3 & (0.62) 0.54 & & \\
\hline OL3 & (0.58) 0.46 & & \\
\hline ME3 & (0.82) 0.74 & & \\
\hline OG3 & 0.79 & & \\
\hline SE3 & (0.82) 0.71 & & \\
\hline SC3 & (0.73) 0.61 & & \\
\hline \multicolumn{4}{|l|}{ Hierarchy } \\
\hline DC4 & $(0.56)$ & & \\
\hline OL4 & (0.78) 0.76 & & \\
\hline ME4 & (0.77) 0.69 & & \\
\hline OG4 & (0.74) 0.6 & & \\
\hline SE4 & (0.84) 0.77 & & \\
\hline $\mathrm{SC} 4$ & (0.80) 0.79 & & \\
\hline
\end{tabular}

Although items with low loadings in the CFA became candidates for deletion, factor loadings in the range of \pm .30 to \pm .35 (sample size 250 to 350 ) can be considered as meeting the minimal level. This can be used to interpret the structure and to preserve the theoretical construct integrity, especially by using the practical significance as the criteria [5, 57]. In this regard, item loadings ranging from .4 to .83 were acceptable. The average variance extracted (AVE) also confirmed the convergent validity and content validity. The lower AVE $(0.34$ for TL) was tolerated when using the CB-SEM approach. This is because Fornell and Larcker had accepted it on the condition that composite reliability was higher than .6 [58]. Composite reliability for all constructs was evident (Table 2, 3, and 4), and Table 5 shows established discriminant validity by means of the [58] procedure. 
The subsequent step used AMOS v23 for the structural model evaluation for CB-SEM which produced the following output: $\mathrm{x}^{2} / \mathrm{df}=1.751 ; \mathrm{GFI}=.816 ; \mathrm{CFI}=.904 ; \mathrm{RMSEA}=.048$. These fit figures were similar to those achieved with the CFA. Therefore, using three or four fit keys provided a passable proof of the model fit [57]. As such, the items were parceled by using the imputation features of AMOS In regression imputation, maximum likelihood was used then linear regression predicted unobserved values.

Table 5. Fornell-Larcker criterion

\begin{tabular}{ccccccc}
\hline & $\mathbf{1}$ & $\mathbf{2}$ & $\mathbf{3}$ & $\mathbf{4}$ & $\mathbf{5}$ & $\mathbf{6}$ \\
\hline \multirow{2}{*}{ TL } & $(0.61)$ & & & & & \\
& $0.58^{*}$ & & & & & \\
SEA & $(0.39)$ & $(0.81)$ & & & & \\
& 0.40 & 0.74 & & & & \\
OEA & $(0.31)$ & $(0.42)$ & $(0.86)$ & & & \\
& 0.32 & 0.42 & 0.81 & & & \\
UOE & $(0.51)$ & $(0.53)$ & $(0.34)$ & $(0.83)$ & & \\
& 0.57 & 0.61 & 0.36 & 0.76 & & \\
ROE & $(0.33)$ & $(0.60)$ & $(0.37)$ & $(0.48)$ & $(0.87)$ & \\
& 0.36 & 0.69 & 0.38 & 0.55 & 0.82 & \\
OC & $(0.27)$ & $(0.25)$ & $(0.22)$ & $(0.25)$ & $(0.27)$ & $(0.67)$ \\
& 0.3 & 0.26 & 0.22 & 0.27 & 0.28 & 0.91 \\
\hline
\end{tabular}

Notes: *Parenthesis values are PLS-SEM; the rest are CB-SEM

Table 6. Structural estimates

\begin{tabular}{|c|c|c|c|}
\hline Hypothesis & $\begin{array}{c}\text { Standard } \\
\text { beta }\end{array}$ & t-statistics & Decision \\
\hline $\mathrm{H} 1$. & (0 110) 0045 & $(1.653)$ & (Reject) \\
\hline $\mathrm{SEA} \rightarrow \mathrm{TL}$ & (0.110) 0.045 & 0.570 & Reject \\
\hline $\mathrm{H} 2$. & & (1.902) & (Reject) \\
\hline $\mathrm{OEA} \rightarrow \mathrm{TL}$ & $0.100) 0.086$ & 1.659 & Reject \\
\hline H3. & & $(7.070)$ & (Accept) \\
\hline $\mathrm{UOE} \rightarrow \mathrm{TL}$ & (0.381) 0.402 & 6.629 & Accept \\
\hline $\begin{array}{c}\mathrm{H} 4 . \\
\mathrm{ROE} \rightarrow \mathrm{TL}\end{array}$ & 0.060 & $\begin{array}{c}(0.188) \\
0.961\end{array}$ & $\begin{array}{c}\text { (Reject) } \\
\text { Reject }\end{array}$ \\
\hline $\begin{array}{c}\mathrm{H} 5 . \\
\mathrm{SEA}^{*} \mathrm{OC} \rightarrow \\
\mathrm{TL}\end{array}$ & (0.132) 0.053 & $\begin{array}{c}(2.735) \\
0.658\end{array}$ & $\begin{array}{c}\text { (Accept) } \\
\text { Reject }\end{array}$ \\
\hline $\begin{array}{c}\text { H6. } \\
\text { OEA*OC } \rightarrow \\
\text { TL }\end{array}$ & $\begin{array}{c}(0.039)- \\
0.010\end{array}$ & $\begin{array}{c}(1.049)- \\
0.210\end{array}$ & $\begin{array}{c}\text { (Reject) } \\
\text { Reject }\end{array}$ \\
\hline $\begin{array}{c}\mathrm{H} 7 . \\
\mathrm{UOE}^{*} \mathrm{OC} \rightarrow \\
\mathrm{TL}\end{array}$ & $\begin{array}{c}(0.082)- \\
0.023\end{array}$ & $\begin{array}{c}(1.820) \\
0.384\end{array}$ & $\begin{array}{c}\text { (Reject) } \\
\text { Reject }\end{array}$ \\
\hline $\begin{array}{c}\mathrm{H} 8 . \\
\mathrm{ROE}^{*} \mathrm{OC} \\
\mathrm{TL}\end{array}$ & (0.126) 0.129 & $\begin{array}{c}(2.975) \\
3.697\end{array}$ & $\begin{array}{c}\text { (Accept) } \\
\text { Accept }\end{array}$ \\
\hline
\end{tabular}

Notes: Parenthesis values are PLS-SEM; the rest are CB-SEM

Results showed that some of the path coefficients were significant at the $10 \%$ level, and some were significant at the $5 \%$ level. The overall $\mathrm{R}^{2}$ for $\mathrm{TL}$ was .3 , which was considered moderately significant since the constructs were predominantly behavioral. Table 6 condenses the hypotheses found from the CB-SEM examination. Two of the eight hypotheses were accepted at the $\mathrm{p}<.01$ significance level, namely $\mathrm{H} 3$ and $\mathrm{H} 8$. The remaining six hypotheses, namely, $\mathrm{H} 1$, $\mathrm{H} 2, \mathrm{H} 4, \mathrm{H} 5, \mathrm{H} 6$, and $\mathrm{H} 7$ were all rejected. At the same time, the structural model for an overall EI was treated as a single construct that included EI dimensions in the second order. This resulted in an $\mathrm{R}^{2}$ of 0.20 , and a positive association between EI and TL at the 0.01 level (standard beta $=0.45$, t-statistic $=$ 9.087) while OC showed a positive and significant interaction with EI (standard beta $=0.213$, t-statistic $=4.144$ ). The convention was followed for frequently used critical values for two-tailed tests, to test a non-directional hypothesis, 2.57, 1.96, and 1.65 for significance levels of $1 \%, 5 \%$, and $10 \%$, respectively [5].

\subsection{PLS-SEM}

PLS-SEM was used because its fit is based on accounting for explained variance in the endogenous constructs and is recommended for prediction-oriented models. PLS is able to analyze data under the conditions of non-normality and can handle complex models while CBSEM tend to run into difficulties like the algorithmic nature that calls for the inverting of matrices, and an increased chance of poor model fit [59]. The measurement model evaluation was carried out using SmartPLS v3, which assessed item and construct validities and reliabilities, and their indicators, for the research model comprising 52 indicators [5]. Following this, the elimination of two indicators (DC1 and IIA1) from the 52 was necessary so as to preserve reliability for indicators with loadings of less than .3 (see Tables 2, 3, \& 4). Convergent validity was confirmed through higher AVE, but the lower AVE ( 0.38 for TL) was tolerated again, as in the CB-SEM analysis above. This is because composite reliability was higher than .6 [58]. Indicators with lower loadings of between 0.40 and 0.70 can be retained when their removal is not required. This helped to increase the composite reliability or AVE, and in circumstances when the scales were applied in a different context [5]. Inspecting the outer models was the starting point for the evaluation of the measurement model. (Tables 2 to 4 had also shown an acceptable composite reliability, ranging from .83 to .95 for the six constructs). Also, Fornell-Larcker's criterion was met and thus the discriminant validity was established.

Prior to assessing the structural model, collinearity was inspected via VIF (variance-inflated factor) which was below 5 , and tolerance values were above .20 , thereby confirming that multicollinearity issues were not present [5]. Therefore, the model's structural relationships can be examined further.

Output gathered from SmartPLS bootstrapping revealed that only three hypotheses were accepted and five were rejected (Table 6). The unconstrained approach for the interaction estimation of the moderator was used because of the ease of specification of product indicators and the lack of constraints from normality assumption [52]. The first direct relationship hypothesis accepted by both the CB-SEM and the PLS-SEM at $\mathrm{p}<.01$, was H3. This predicted a positive relationship between UOE and TL. Next, hypotheses H5 and $\mathrm{H} 8$ were accepted at $\mathrm{p}<.01$. Findings revealed that there were significant and positive moderating effects by $\mathrm{OC}$ on the relationships between SEA and TL, and ROE and TL, respectively. The remaining five hypotheses, namely, $\mathrm{H} 1, \mathrm{H} 2$, $\mathrm{H} 4, \mathrm{H} 6$, and $\mathrm{H} 7$ were all rejected.

The Coefficient of Determination $\mathrm{R}^{2}$ value for the endogenous construct, TL, was considered substantial (.293), as shown in Figure 1. This is in accordance with [52], who suggested $\mathrm{R}^{2}$ values for endogenous latent variables to be assessed as follows: 0.26 (substantial), 0.13 (moderate), 0.02 (weak) [52]. Not surprisingly, given the above findings, a structural model that included an overall EI with EI dimensions, was also examined in the second order. It also revealed an $R^{2}$ value of 0.260 and exhibited a positive association between EI and TL (standard beta $=0.417, \mathrm{t}$ statistic $=8.452)$, and the OC moderated EI (standard beta $=$ 
0.129, t-statistic $=2.648$ ). Finally, predictive relevance showed accepted level $\mathrm{Q}^{2}$ effect size $(.109$, distance $\mathrm{D}=7)$, which was not available from the CB-SEM [5].

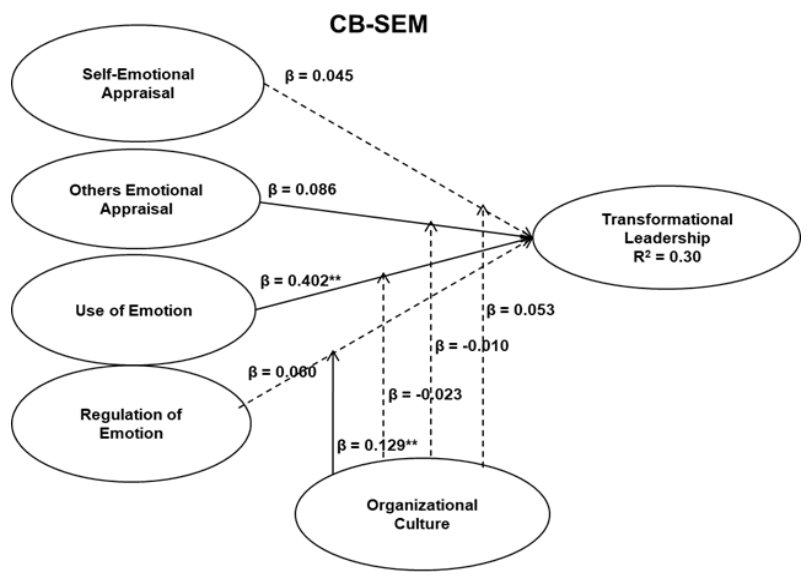

Note, $\mathrm{N}=3333^{*} \mathrm{p}<.05 ; * \star \mathrm{p}<.01$

$R^{2}=$ The Coefficient of Determination

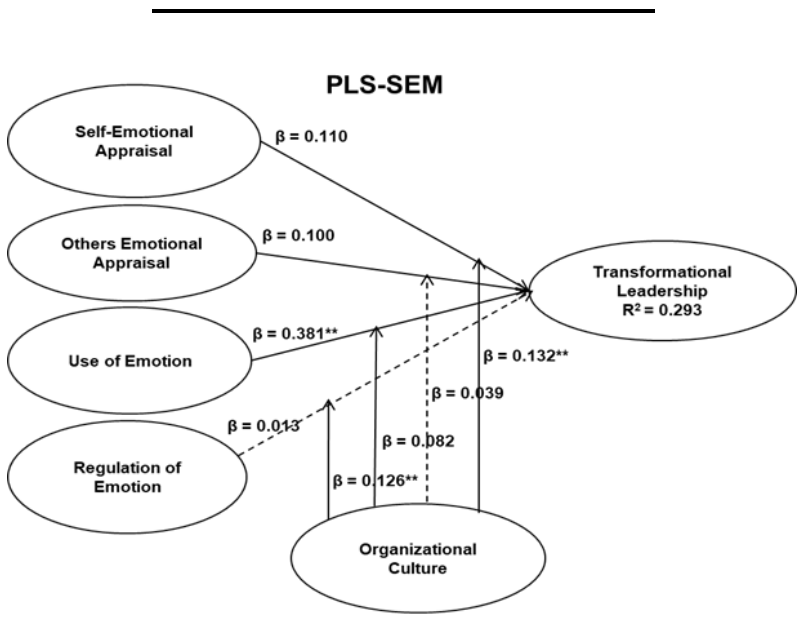

Note. $\mathrm{N}=333{ }^{*} \mathrm{p}<.05 ;{ }^{* \star} \mathrm{p}<.01$

$\mathbf{R}^{2}=$ The Coefficient of Determination

Figure 1. Structural models

\section{RESULTS DISCUSSION}

After analyzing the results, there appear to be several differences and similarities between the CB-SEM and the PLS-SEM approaches which the current study had hoped to uncover, and which suboptimal situations would have. The outcome would feature each approach that fell short, for the reasons suggested by Rigdon et al. [1]. The CB-SEM and the PLS-SEM analyses provided strong results which confirmed that the EI dimensions predicted TL and that the OC can act as a moderator between EI and TL and between certain dimensions of EI and TL. Both analytical approaches revealed that the variance in the endogenous TL construct can be explained by the EI dimensions by $30 \%$ (CB-SEM) and $29 \%$ (PLS-SEM), in that order.

The overall showed similarities, but a detailed look revealed some differences. First, the model fit in CB-SEM resulted in some deletions of four items, yet all the constructs had sufficient indicators for SEM [5, 57]. Simultaneously, the PLS-SEM analysis settled for the removal of just two indicators. This deletion may lead to bias in terms of inference estimation when making the validation. This deletion did not exceed $20 \%$ of the overall items of the study; hence it did not develop issues of content validity [52].

On one hand, both the CB-SEM and PLS-SEM had resulted in a significant association between $\mathrm{EI}$ as an overall construct, and TL $(\mathrm{B}=0.45$, and $\mathrm{B}=0.417$, respectively), and for the overall moderating effect of OC between EI and TL $(B=0.213$, and $\mathrm{B}=0.129)$. The $\mathrm{R}^{2}$ values were likewise, within the moderately significant range (Figure 1). For both approaches, a strong effect was observed between UOE and TL (B =6.629 and $\mathrm{B}=7.070$, respectively), and for the moderating effect of $\mathrm{OC}$ on ROE and TL $(\mathrm{B}=3.697$, and $\mathrm{B}=2.975$, respectively). This raised the question of whether the model fit can sometimes be forgone for theory development, especially when it comes to indicator removal. This can mean that models with more retained indicators have more reliability and validity because they lose fewer indicators, hence promoting face validity and meaningful contents $[6,52]$.

On the other hand, differences were evident in some of the structural estimates (Table 6 and Figure 1) of the CB-SEM. Here, UOE exhibited the strongest $(\mathrm{B}=0.402)$ relationship with TL, whereas SEA proved to be the weakest predictor (B $=0.045)$ of leadership. In contrast, the PLS-SEM revealed that UOE was the strongest predictor of TL $(B=0.381)$ while ROE appeared to be the weakest predictor of leadership $(B=0.013)$. The CB-SEM approach exhibited significant relationships only in two variables, whereas the PLS-SEM approach revealed three significant variables at $p<.05$. This difference seemed to be more pronounced when the analysis included significance at $\mathrm{p}<.1$. IN this regard, the PLS-SEM would have supported six hypotheses while the CB-SEM would have supported only three hypotheses. One possible reason for the lower acceptance of the significance as well as other differences in the results in the CB-SEM approach may be due to the higher number of items removed. Another plausible reason for the difference could be traced to what [60] had noted about PLS. That is, the PLS bias causes the overestimation of the measurement parameters and the underestimation of the structural parameters.

\section{CONCLUSION}

This study has presented the application of two SEM methods in an empirical study which focused on leadership. The aim was to highlight some of the benefits and suitability of each approach. The findings offer important implications and guidelines for leadership development researchers to use both the CB-SEM and the PLS-SEM, with equal utilization for future studies. As such, it was concluded that future studies need to observe the five recommendations made by Rigdon et al. [1], that "researchers should focus on more fundamental aspects of research design", instead of comparing the CB-SEM and the PLS-SEM methods. The research gap is found in the inconsistencies and mixed results of past studies regarding the EI-TL association and so this study adds a moderator and validates the investigation using two prominent but contentious approaches.

The current study had explored the use of the CB-SEM and the PLS-SEM approaches, and the outcome showed that UOE predicted TL, as noted in past studies [61, 62]. Results also showed that OC can moderate the ROE-TL relationship. These results were expected because UOE, as represented by Understanding Emotions, enabled leaders to act as strong role 
models who can be trusted to do the right thing because of the greater trust placed in that leader. Likewise, ROE requires that emotions be displayed in effective ways, and this should also be supported by Organizational Culture which acts as a situational determinant. A strong organizational culture has standards which are clear for measuring appropriate behaviors of followers [40].

Several conclusions can be drawn from the validation of the two SEM approaches. Past studies using the PLS path modeling for SEM purposes were obliged to justify substantially, their rationale for choosing the PLS [59]. In this regard, the current study had shown that the PLS-SEM method displayed a robust variant analysis, followed by enhanced validity and reliability results. The model did not lose much content which might have affected theory development, and managerial implications. Simultaneously, an EFT performed earlier in the data analysis had resulted in the loss of eight items from TL, thereby leading to its uni-dimensionality. All of these were due to the inability of the CB-SEM to reach an acceptable model fit during the initial CFA. In contrast, the PLS model had capitalized on the inclusion of weak items to extract whatever useful information that was available in the indicators to create a better construct score.

In the PLS-SEM model, the first and second-order constructs were easily accomplished, and the latent variable scores were obtained. Both are essential for predictive relevance when building higher-order constructs [59]. Conversely, this process can prove to be difficult and typically uncertain in the CB-SEM model. The current study had utilized five second order and four second-order latent constructs, TL, and OC, respectively, with 44 primary indicators. While both the CB-SEM and the PLS-SEM models had managed to make possible, the extension of the higherorder factor, it appears that the PLS-SEM was not acutely restricted by model complexity, when compared to the CBSEM [52, 59]. Such merit is attributed to the segmentation process and algorithm of the PLS which enabled the division of complex models, such that only one subset of a parameter was estimated at a single moment [16].

The PLS path modeling is recommended if the research is prediction-oriented or is an extension of an existing theory [52]. Accordingly, the current study is a correlational study, where prediction was reasoned to be more vital than parameter estimation, i.e., EI dimensions that could predict TL and OC, were examined as moderators on the relationship [5, 52]. Using the PLS may seem more appropriate for the current study because larger models with 50 or more items may run into difficulties when using the CB-SEM. These difficulties include the algorithmic nature that calls for the inverting of matrices, an increased chance of poor model fit, and memory limitations of most current computers. All of these could result in long running time, or no run at all [59].

As a research based in the realm of social science, there are several limitations worth noting in this study. The first limitation is related to the results of the current work which are effective only inside the parameters of the study examined. Additionally, a validation of the two approaches is useful because both methods differ in assumptions, outcomes, and estimation procedures. From the results derived, we can learn how their results may or may not differ in different situations. Therefore, future research can take an interesting direction of validating the two SEM techniques by using normal as well as non-normal data with smaller sample sizes to test the restrictions claimed against the CB-SEM.
The main practical significance of this study is that it provides guidance on SEM approach selection. The first criteria are related to assessing whether the approach is suitable for answering their research question of whether it is theory development or theory confirmation. PLS-SEM is recommended for theory development and CB-SEM for theory confirmation because PLS-SEM allows the retention of indicator items and higher factor loadings. The second important criteria are related to their sample, data, and measurement characteristics. Use PLS-SEM when lacking normality and smaller sample sizes, and if it is useful to construct higher order hierarchical component models (HCM) [5]. Consequently, policy makers in the research community are invited to promote methodological innovations to expand on questions researchers ask and improve the credibility of their solutions by demanding deeper investigation of quality criteria and usage of methods that avoid bias in quantitative research.

While explanations for the criteria used are recognized in accordance with empirics, because of the lack of a selection criterion used to specify the population of interest as it covers only a small portion of the academic leaders, hence the generalizability of the study is reduced. Another akin limitation relates to the smaller sample size which was due to the expense and difficulty of collecting data in person from the very busy leaders. Finally, due to the cross-sectional nature of the study caution is well-advised to the interpretation of direct and moderation as evidence of causal relationships. It would be remarkable for future research to repeat the current research's model in different countries with a bigger sample from private as well as public universities with longitudinal data to track changes over longer periods

As a final word, the present study has accomplished its aim of validating the potential advantages and weaknesses of the CB-SEM and the PLS-SEM in leadership development research. However, even though the PLS-SEM seemed to be slightly more suitable for the context of this study, researchers need to proceed with caution when deciding on the appropriateness of either approach for their research situations. The research implications of this study are recognized in the empirical and practical contributions. This study had first validated the SEM approaches in a complex model which included the moderator effects by using real data. This study had also recognized the differences of the two approaches for the setup of model specification and parameter estimation before conducting the analyses. The findings of this study advance understanding of the application of standards and guiding principles when clarifying interpretations of SEM theories and models. The validation using of the two SEM approaches highlighted the differences in terms of requirements, applications, and analysis of both approaches. This, therefore, verified the similar anticipated conclusions yielded by both methods. The differences shown further encourage the optimal use of available data analysis tools. Nonetheless, this is only evident when observing the recommendations of certain researchers like Rigdon et al. [1] which is to focus on the phenomenon and research designs, and not just the modeling aspects only.

\section{REFERENCES}

[1] Rigdon, E.E., Sarstedt, M., Ringle, C.M. (2017). On comparing results from CB-SEM and PLS-SEM: Five 
perspectives and five recommendations. Marketing Zfp, 39(3): 4-16. https://doi.org/10.15358/0344-1369-2017$3-4$

[2] Bell, E., Bryman, A., Harley, B. (2018). Business Research Methods. Oxford University Press.

[3] Christofi, M., Hadjielias, E., Hughes, M., Plakoyiannaki, E. (2021). Advancing research methodologies in management scholarship. British Journal of Management.

[4] Turner, S.F., Cardinal, L.B., Burton, R.M. (2017). Research design for mixed methods: A triangulationbased framework and roadmap. Organizational Research Methods, 20(2):

243-267. https://doi.org/10.1177/1094428115610808

[5] Hair Jr, J.F., Hult, G.T.M., Ringle, C., Sarstedt, M. (2017). A Primer on Partial Least Squares Structural Equation Modeling (PLS-SEM). Sage Publications. ISBN: 9781483377445

[6] Byrne, B.M. (2010). Structural Equation Modelling with AMOS: Basic Concepts, Applications, and Programming, 2nd ed.. Routledge, New York, NY.

[7] McIntosh, C.N., Edwards, J.R., Antonakis, J. (2014) Reflections on partial least squares path modeling. Organizational Research Methods, 17(2): 210-251. https://doi.org/10.1177/1094428114529165

[8] Follesdal, H., Hagtvet, K. (2013). Does emotional intelligence as ability predict transformational leadership? A multilevel approach. The Leadership Quarterly, 24(5): 747-762. https://doi.org/10.1016/j.leaqua.2013.07.004

[9] Harms, P.D., Credé, M. (2010). Emotional intelligence and transformational and transactional leadership: A meta-analysis. Journal of Leadership \& Organizational Studies, 17(1):

$5-17$.

https://doi.org/10.1177/1548051809350894

[10] Berglund, M. (2014) A study to explore the relationship between leadership and organizational culture in a government organization. Unpublished Doctoral Dissertation, Grand Canyon University, Phoenix, AZ.

[11] Zagorsek, H., Jaklic, M., Stough, S.J. (2004). Comparing leadership practices between the United States, Nigeria, and Slovenia: Does culture matter? Cross Cultural Management: An International Journal, 11(2): 16-34. https://doi.org/10.1108/13527600410797774

[12] Subramanian, I.D., Yen, C.L. (2013). Emotional intelligence of leaders and organizational culture: Evidence from IT companies in Malaysia. African Journal of Business Management, 7(11): 882-890. https://doi.org/10.5897/AJBM12.1177

[13] Waldron, V.R., Krone, K.J. (1991). The experience and expression of emotion in the workplace: A study of a corrections organization. Management Communication Quarterly, 4(3): 287-309. https://doi.org/10.1177/0893318991004003002

[14] Gefen, D., Straub, D.W., Rigdon, E.E. (2011). An update and extension to SEM guidelines for admnistrative and social science research. MIS Quarterly 35(2): iii-xiv.

[15] Sarstedt, M., Hair, J.F., Ringle, C.M., Thiele, K.O., Gudergan, S.P. (2016). Estimation issues with PLS and CBSEM: Where the bias lies! Journal of Business Research, 69(10): https://doi.org/10.1016/j.jbusres.2016.06.007

[16] Chin, W.W., Marcolin, B.L., Newsted, P.R. (2003). A partial least squares latent variable modeling approach for measuring interaction effects: Results from a Monte
Carlo simulation study and an electronic-mail emotion/adoption study. Information Systems Research, 14(2):

189-217. https://doi.org/10.1287/isre.14.2.189.16018

[17] Dijkstra, T.K., Henseler, J. (2015). Consistent and asymptotically normal PLS estimators for linear structural equations. Computational Statistics \& Data Analysis, 81:

$10-23$. https://doi.org/10.1016/j.csda.2014.07.008

[18] Henseler, J., Dijkstra, T.K., Sarstedt, M., Ringle, C.M., Diamantopoulos, A., Straub, D.W. (2014). Common beliefs and reality about PLS: Comments on Rönkkö and Evermann (2013). Organizational Research Methods, 17(2): 182-209. https://doi.org/10.1177/1094428114526928

[19] Hwang, H., Malhotra, N.K., Kim, Y., Tomiuk, M.A., Hong, S. (2010). A comparative study on parameter recovery of three approaches to structural equation modeling. Journal of Marketing Research, 47(4): 699712. https://doi.org/10.2307/20751534

[20] Willaby, H.W., Costa, D.S., Burns, B.D., MacCann, C., Roberts, R.D. (2015). Testing complex models with small sample sizes: A historical overview and empirical demonstration of what partial least squares (PLS) can offer differential psychology. Personality and Individual Differences, 84: 73-78. https://doi.org/10.1016/j.paid.2014.09.008

[21] Henseler, J., Hubona, G.S., Ray, P.A. (2016). Using PLS path modeling in new technology research: Updated guidelines. Industrial Management and Data Systems, 116: 2-20. https://doi.org/10.1108/IMDS-09-2015-0382

[22] Hair, J.F., Hult, G.T.M., Ringle, C.M., Sarstedt, M., Thiele, K.O. (2017). Mirror, mirror on the wall: A comparative evaluation of composite-based structural equation modeling methods. Journal of the Academy of Marketing Science, 45(5): 616-632. https://doi.org/10.1007/s11747-017-0517-x

[23] Sarstedt, M., Ringle, C.M., Hair, J.F. (2017). Partial Least Squares Structural Equation Modeling. Handbook of Market Research, 26(1): 1-40.

[24] Rönkkö, M., Evermann, J. (2013). A critical examination of common beliefs about partial least squares path modeling. Organizational Research Methods, 16(3): 425448. https://doi.org/10.1177/1094428112474693

[25] Marcoulides, G.A., Chin, W.W., Saunders, C. (2012). When imprecise statistical statements become problematic: A response to Goodhue, Lewis, and Thompson. MIS Quarterly, 36(3): 717-728.

[26] Marcoulides, G.A., Chin, W.W. (2013) You write, but others read: Common methodological misunderstandings in PLS and related methods. In New Perspectives in Partial Least Squares and Related Methods, pp. 31-64.

[27] Treiblmaier, H., Bentler, P.M., Mair, P. (2011). Formative constructs implemented via common factors. Structural Equation Modeling, 18(1): 1-17. https://doi.org/1080/10705511.2011.532693

[28] Ministry of Higher Education. (2015). Malaysia Education Blueprint 2015-2025 (Higher Education). https://www.um.edu.my/docs/um-magazine/4executive-summary-pppm-2015-2025.pdf, accessed in 9 September 2016.

[29] Petrie, N. (2011). Future trends in leadership development. 
http://leanconstruction.org/media/learning_laboratory/L eadership/Future_Trends_in_Leadership_Development. pdf, accessed in $\overline{1} 6$ March 2020 .

[30] Bass, B.M., Riggio, R.E. (2006). Transformational Leadership. Mahwah, NJ: Lawrence Erlbaum Associates. https://doi.org/10.4324/9781410617095

[31] Burns, J.M. (1978). Leadership. New York. NY: Harper and Row Publishers.

[32] Wang, G., Oh, I., Courtright, S., Colbert, A. (2011) Transformational leadership and performance across criteria and levels: A meta-analytic review of 25 years of research. Group \& Organization Management, 36(2): 223-270. https://doi.org/10.1177/1059601111401017

[33] Yukl, G.A. (1989) Leadership in Organizations. Noida, India: Pearson Education India.

[34] Ashkanasy, N.M., Dorris, A.D. (2017). Emotions in the workplace. Annual Review of Organizational Psychology and Organizational Behavior, 4: 67-90. https://doi.org/10.1146/032516-113231

[35] Hatch, M.J. (1993). The dynamics of organizational culture. Academy of Management Review, 18(4): 657693. https://doi.org/10.5465/amr.1993.9402210154

[36] Schein, E.H. (2004) Organizational Culture and Leadership. San Francisco, CA: Jossey-Bass. ISBN: $978-$ 1-349-35291-3.

[37] Cameron, K., Quinn, R. (2011). Diagnosing and Changing the Organizational Culture: Based on the Competing Values Framework. New York City, NY: John Wiley \& Sons.

[38] Walter, F., Cole, M., Humphrey, R. (2011). Emotional intelligence: Sine qua non of leadership or folderol? The Academy of Management Perspectives, 25(1): 45-59. https://doi.org/10.1016/j.leaqua.2010.12.017

[39] Sadri, G., Weber, T., Gentry, W. (2011). Empathic emotion and leadership performance: An empirical analysis across 38 countries. The Leadership Quarterly, 22(5):

818-830. https://doi.org/10.1016/j.leaqua.2011.07.005

[40] Bandura, A. (1986). Social Foundations of Thought and Action: A Social Cognitive Theory. Upper Saddle River, NJ: Prentice-Hall, Inc.

[41] RaesIi, I., Honarvar, M.S., Fallah, M.F., Behnood, V. (2016). The Relationship between Different Leadership Styles and Emotional Intelligence (EI) in Managers of Educational Groups (Case Study: Tehran Schools). International Journal of Humanities and Cultural Studies (IJHCS), pp. 514-527. ISSN 2356-5926.

[42] Weinberger, L. (2009). Emotional intelligence, leadership style, and perceived leadership effectiveness. Advances in Developing Human Resources, 11(6): 747772. https://doi.org/10.1177/1523422309360811

[43] Wong, C., Law, K. (2002). The effects of leader and follower emotional intelligence on performance and attitude: An exploratory study. The Leadership Quarterly, 13(3): 243-274. https://doi.org/10.1016/S10489843(02)00099-1

[44] Goleman, D., Boyatzis, R.E., McKee, A. (2013). Primal Leadership: Unleashing the Power of Emotional Intelligence. Harvard Business Press.

[45] Bass, B.M., Avolio, B.J. (2000). Multifactor Leadership Questionnaire: MLQ: Sampler Set. Technical Report, Leader Form, Rater Form, and Scoring Key for MLQ Form 5x-short.

[46] Tabachnick, B.G. Fidell, L.S. (2007). Using Multivariate
Statistics (5th edn). Boston, MA: Pearson Education. ISBN: 0205459382.

[47] Sekaran, U., Bougie, R. (2010). Research Methods for Business: A Skill Building Approach. United Kingdom: John Wiley \& Son Ltd.

[48] Bakar, M.S. (2014). The mediating effect of intrapreneurial orientation on the relationships between leadership style, knowledge sharing behavior and performance of academic leaders in Malaysia. Unpublished Doctoral Dissertation, Universiti Utara Malaysia, Malaysia.

[49] Krejcie, R.V., Morgan, D.W. (1970). Determining sample size for research activities. Educational and Psychological Measurement, 30(3): 607-610.

[50] McCrum-Gardner, E. (2010). Sample size and power calculations made simple. International Journal of Therapy and Rehabilitation, 17(1): 10. https://doi.org/10.12968/ijtr.2010.17.1.45988

[51] Pallant, J. (2013). SPSS Survival Manual: A Step by Step Guide to Data Analysis Using SPSS for Windows (4th ed.). England, UK: McGraw Hill Open University Press. https://doi.org/10.1111/1753-6405.12166

[52] Hair, J.F., Black, B., Babin, B.J. (2010). Multivariate Data Analysis. Upper Saddle River: Prentice Hall. ISBN: 978-7-111-34198-7.

[53] Izquierdo Alfaro, I., Olea Díaz, J., Abad García, F.J. (2014). Exploratory factor analysis in validation studies: Uses and recommendations. Psicothema, 26(3): 395-400. https://doi.org/10.7334/psicothema2013.349

[54] Schriesheim, C.A., Powers, K.J., Scandura, T.A., Gardiner, C.C., Lankau, M.J. (1993). Improving construct measurement in management research: Comments and a quantitative approach for assessing the theoretical content adequacy of paper-and-pencil surveytype instruments. Journal of Management, 19(2): 385417. https://doi.org/10.1177/014920639301900208

[55] Van Beveren, P., Dimas, I. D., Lourenço, P.R., Rebelo, T. (2017). Psychometric properties of the Portuguese version of the Global Transformational Leadership (GTL) scale. Revista de Psicología del Trabajo y de las Organizaciones, 33(2):

109-114. https://doi.org/10.1016/j.rpto.2017.02.004

[56] MacKenzie, S.B., Podsakoff, P.M., Jarvis, C.B. (2005). The problem of measurement model misspecification in behavioral and organizational research and some recommended solutions. Journal of Applied Psychology, 90(4): 710. https://doi.org/10.1037/0021-9010.90.4.710

[57] Hair, J. (2009). Multivariate Data Analysis: A Global Perspective. Upper Saddle River: Prentice Hall.

[58] Fornell, C., Larcker, D.F. (1981). Evaluating structural equation models with unobservable variables and measurement error. Journal of Marketing Research, 18(1): 39-50. https://doi.org/10.2307/3151312

[59] Chin, W.W. (2010). How to write up and report PLS analyses. In Handbook of partial least squares, pp. 655690.

[60] Sarstedt, M., Ringle, C.M., Hair, J.F. (2017). Treating Unobserved Heterogeneity in PLS-SEM: A Multimethod Approach. In: Latan H., Noonan R. (eds) Partial Least Squares Path Modeling. Springer, Cham. https://doi.org/10.1007/978-3-319-64069-3_9

[61] Burbach, M.E. (2004). Testing the relationship between emotional intelligence and full-range leadership as moderated by cognitive style and self-concept. 
Unpublished Doctoral Dissertation, University of Nebraska, Lincoln.

[62] Hur, Y., van den Berg, P.T., Wilderom, C.P. (2011). Transformational leadership as a mediator between emotional intelligence and team outcomes. The Leadership Quarterly, 22(4): 591-603. https://doi.org/10.1016/j.leaqua.2011.05.002

\section{APPENDIX 1}

\begin{tabular}{|c|c|}
\hline Study & Discussion of findings \\
\hline $\begin{array}{l}\text { Hwang, H., N.K.Malhotra, Y. Kim, } \\
\text { M.A. Tomiuk, and S. Hong (2010) }\end{array}$ & $\begin{array}{l}\text { This article finds that PLS exhibits inferior performance in parameter recovery compared with SEM. } \\
\text { It concludes that generalized structured component analysis may be a good alternative to PLS, for } \\
\text { structural equation modeling, hence it is recommended over CB-SEM, unless the correct model } \\
\text { specification is ensured. It acknowledges the differences in the setup of the approaches in terms of } \\
\text { model specifications and parameter estimations, ahead of any analyses conducted. }\end{array}$ \\
\hline $\begin{array}{l}\text { Marcoulides, G. A., Chin, W. W., \& } \\
\text { Saunders, C. (2012). } \\
\text { AND } \\
\text { Marcoulides, G. A., \& Chin, W. W. } \\
\text { (2013) }\end{array}$ & $\begin{array}{l}\text { The writers state that both approaches will always yield identical results and the differences arise } \\
\text { only from the setup of the approaches in terms of model specification and parameter estimation. }\end{array}$ \\
\hline Rönkkö, M., \& Evermann, J. (2013) & $\begin{array}{l}\text { This paper concludes that the PLS-SEM is widely misunderstood, and their results cast doubts on its } \\
\text { effectiveness for building and testing theory in organizational research. }\end{array}$ \\
\hline $\begin{array}{l}\text { Henseler, J., Dijkstra, T. K., Sarstedt, } \\
\text { M., Ringle, C. M., Diamantopoulos, } \\
\text { A., Straub, D. W. \& Calantone, R. J. } \\
\text { (2014a) }\end{array}$ & $\begin{array}{l}\text { This paper contends that alleged shortcomings of PLS are not due to problems it has, but rather the } \\
\text { techniques, and that PLS should continue to be used as an important statistical tool for management } \\
\text { and organizational research. }\end{array}$ \\
\hline $\begin{array}{l}\text { Astrachan, B. Patel, \& Wanzenried } \\
\text { (2014) }\end{array}$ & $\begin{array}{l}\text { They compare CB-SEM and PLS-SEM, and concluded that there are advantages in using PLS for } \\
\text { family business research. }\end{array}$ \\
\hline $\begin{array}{l}\text { McIntosh, C. N., Edwards, J. R., \& } \\
\text { Antonakis, J. (2014). }\end{array}$ & $\begin{array}{l}\text { This paper makes recommendations for improving the ability of PLS to estimate and test theoretical } \\
\text { models. Path modeling with composite variables have limitations similar to those of PLS in terms of } \\
\text { the ability to validate causal structures. The advantages of PLS are relative to SEM which also exist } \\
\text { in SEM (e.g. reduced computational demands and superior convergence behavior, robustness to } \\
\text { small sample size, tolerance of badly behaved distributions, exploratory capabilities in the absence } \\
\text { of a theory, etc.). PLSc cannot match SEM's estimation and testing capabilities based on common } \\
\text { factor-based modeling because it is not equipped to deal with the ubiquitous problem of correlated } \\
\text { measurement errors. }\end{array}$ \\
\hline Kaufmann \& Gaeckler (2015) & $\begin{array}{l}\text { The study compares CB-SEM and PLS-SEM and provides a review of PLS-SEM use in supply } \\
\text { chain management research. }\end{array}$ \\
\hline $\begin{array}{l}\text { Willaby, Costa, Burns, MacCann, \& } \\
\text { Roberts (2015) }\end{array}$ & $\begin{array}{l}\text { Their results for testing complex models in psychology show that PLS produces results similar to } \\
\text { SEM for a simple mediation model. PLS also performs well in a complex model for which SEM } \\
\text { would require a large sample. }\end{array}$ \\
\hline $\begin{array}{l}\text { Sarstedt M., Hair J. F., Ringle C. M., } \\
\text { Thiele, K. O., \& Gudergan, S. P. } \\
\text { (2016) }\end{array}$ & $\begin{array}{l}\text { Their results highlight the biases that occur when } \\
\text { using (1) composite-based partial least squares path modeling to estimate common factor models, } \\
\text { and (2) common factor-based covariance-based structural equation modeling to estimate composite } \\
\text { models. The results show that the use of PLS is preferable, particularly when it is unknown whether } \\
\text { the data's nature is common factor- or composite-based. }\end{array}$ \\
\hline $\begin{array}{l}\text { Henseler, J., Hubona, G. S., \& Ray, } \\
\text { P.A. (2016) }\end{array}$ & $\begin{array}{l}\text { The article presents the latest developments in PLS-SEM. They argue that there is no clear-cut } \\
\text { resolution of the issues on this trade-off between efficiency and robustness with respect to model } \\
\text { mis-specification. }\end{array}$ \\
\hline Nitzl, C. (2016) & $\begin{array}{l}\text { After reviewing the reasons for using PLS-SEM, and after giving the characteristics of the data and } \\
\text { models followed by the model evaluation and reporting, the author makes four recommendations for } \\
\text { using PLS-SEM. }\end{array}$ \\
\hline $\begin{array}{l}\text { Richter, Sinkovics, Ringle, \& } \\
\text { Schlägel (2016) }\end{array}$ & $\begin{array}{l}\text { They review the use of the CB-SEM and PLS-SEM use in international business research. Their } \\
\text { findings show that papers in the field do not emphasize PLS's key benefits, which might be fruitful } \\
\text { for the theorizing process, and are not following best practices to advance theory building. }\end{array}$ \\
\hline $\begin{array}{l}\text { Rigdon E. E., Sarstedt M., \& Ringle } \\
\text { C. M. (2017) }\end{array}$ & $\begin{array}{l}\text { The authors suggest not comparing SEM and PLS but instead offer to look at five perspectives and } \\
\text { make five recommendations instead. }\end{array}$ \\
\hline $\begin{array}{l}\text { Hair J. F., Hult G. T. M., Ringle C. } \\
\text { M., Sarstedt M., \& Thiele, K. O. } \\
\text { (2017b) }\end{array}$ & $\begin{array}{l}\text { The article focuses on learning more about the methods' relative performance and the settings that } \\
\text { favor each method's use. They use composite model data. Their results show that each approach has } \\
\text { certain strengths and weaknesses, which make it suitable when the focus is on parameter accuracy in } \\
\text { the measurement models, the structural model, or on statistical power. }\end{array}$ \\
\hline $\begin{array}{l}\text { Sarstedt M., Ringle C.M., \& Hair J. } \\
\text { F. (2017) }\end{array}$ & $\begin{array}{c}\text { This work highlights that CB-SEM has been labeled as hard modeling because of its numerous and } \\
\text { rather restrictive assumptions, and for data distribution and sample size. At the same time, they point } \\
\text { out how PLS-SEM bias involves overestimating the measurement model parameters and } \\
\text { underestimates the structural model parameters. }\end{array}$ \\
\hline $\begin{array}{l}\text { Hair, Hollingsworth, Randolph, \& } \\
\text { Chong }(2017 \mathrm{c})\end{array}$ & $\begin{array}{l}\text { They update and expand the assessment of PLS-SEM use in information systems research while } \\
\text { offering rules of thumb for choosing between CB-SEM and PLS-SEM. }\end{array}$ \\
\hline $\begin{array}{l}\text { Ali, F., Kim, W. G., Li, J., \& } \\
\text { Cobanoglu, C. (2018) }\end{array}$ & $\begin{array}{l}\text { They compare CB-SEM and PLS-SEM and determined that there are greater advantages for } \\
\text { hospitality and tourism researchers in applying PLS-SEM. }\end{array}$ \\
\hline
\end{tabular}

